\title{
Correction to: Bazedoxifene as a novel GP130 inhibitor for Colon Cancer therapy
}

Jia Wei ${ }^{1,2}$, Ling Ma ${ }^{2}$, Yi-Hui Lai ${ }^{3}$, Ruijie Zhang ${ }^{2}$, Huameng Li ${ }^{4}$, Chenglong $\mathrm{Li}^{5}$ and Jiayuh Lin ${ }^{2^{*}}$

\section{Correction to: J Exp Clin Cancer Res https://doi.org/10.1186/s13046-019-1072-8}

In the original publication of this article [1], there is an error in Fig. 4A.

The corrected Fig. 4A should be:

\section{Author details}

${ }^{1}$ Department of Hematology, Tongii Hospital, Tongji Medical College, Huazhong University of Science and Technology, Wuhan 430030, People's Republic of China. ${ }^{2}$ Department of Biochemistry and Molecular Biology, University of Maryland School of Medicine, 108 N. Greene Street, Baltimore, MD 21201, USA. ${ }^{3} 33$ Linsen Road, Chungshan District, Taipei, Taiwan. ${ }^{4}$ Biophysics Graduate Program, The Ohio State University, Columbus, $\mathrm{OH}$ 43210, USA. ${ }^{5}$ College of Pharmacy, University of Florida, Gainesville, FL 32610, USA.

Published online: 23 August 2019

\section{Reference}

1. Wei, et al. Bazedoxifene as a novel GP130 inhibitor for Colon Cancer therapy. J Exp Clin Cancer Res. 2019;38:63. https://doi.org/10.1186/s13046-01 9-1072-8.

\footnotetext{
*Correspondence: JLin@som.umaryland.edu

${ }^{2}$ Department of Biochemistry and Molecular Biology, University of Maryland

School of Medicine, 108 N. Greene Street, Baltimore, MD 21201, USA

Full list of author information is available at the end of the article
} 


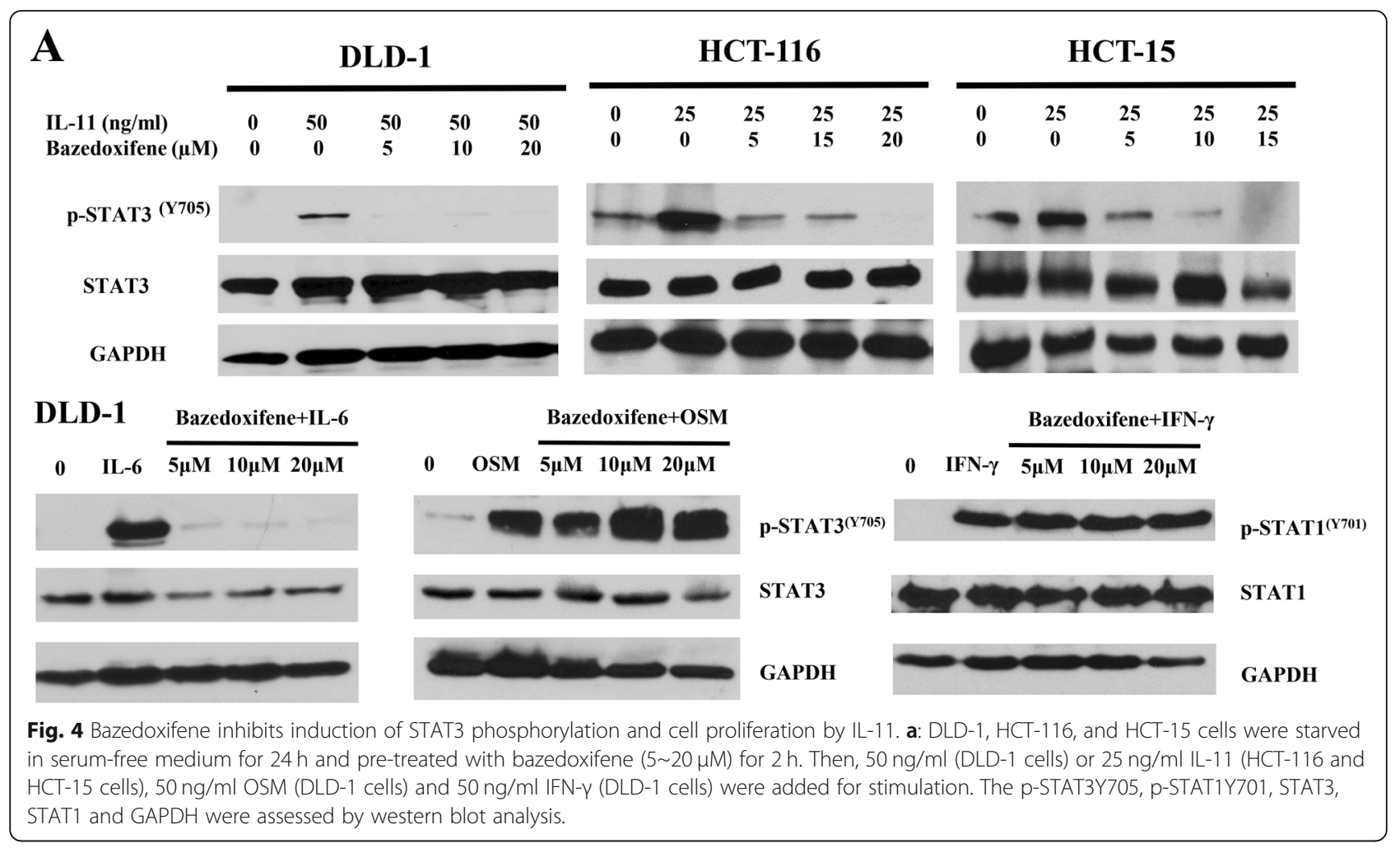

